\title{
Spinal cord stimulation or prostacyclin in unrevascularizable arteriopathy of lower limbs (SPINAL) study: interim analysis results
}

This article was published in the following Dove Press journal:

Journal of Vascular Diagnostics

25 April 2014

Number of times this article has been viewed

\section{Luciano Pedrini}

Maria Sandra Ballestrazzi'

Fabio Chierichetti ${ }^{2}$

Luigi Comandatore ${ }^{3}$

Filippo Magnoni'

Reinhold Perkmann ${ }^{4}$

Tommaso Castrucci ${ }^{5}$

Domenico Palombo 6

On behalf of the SPINAL Study

\section{Group}

'Operative Unit of Vascular Surgery, Maggiore Hospital of Bologna, Bologna, Italy; ${ }^{2}$ Operative

Unit of Vascular Surgery, Circle Hospital of Busto Arsizio, Busto Arsizio, Italy; ${ }^{3}$ Operative Unit of Vascular Surgery, AEO Morelli of Sondalo, Sondalo, Italy; ${ }^{4}$ Operative Unit of Vascular and Thoracic Surgery, Hospital of Bolzano, Bolzano, Italy; ${ }^{5}$ Operative Unit of Vascular Surgery of Sant'Eugenio Hospital, Rome, Italy; ${ }^{6}$ Operative Unit of Vascular and Endovascular Surgery, IRCCS San Martino, Genoa, Italy

\section{Video abstract}

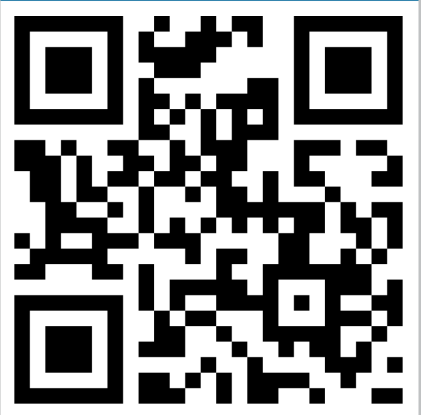

Point your SmartPhone at the code above. If you have a QR code reader the video abstract will appear. Or use: http://dvpr.es/Imb9t|B

Correspondence: Luciano Pedrini Via del Colle, 26 - 40068, San Lazzaro di Savena (BO), Italy

Tel +39 05I 480552

Fax +3905I 6478036

Email pedrini.vascolare@gmail.com
Objective: The aim of this study was to compare the clinical efficacy and the safety of spinal cord stimulation (SCS) plus medical treatment versus iloprost plus medical treatment in patients with severe unrevascularizable ischemia of the lower limbs due to atherosclerotic disease of the limbs and to identify predictive parameters for a positive outcome of SCS.

Methods: A multicenter randomized controlled trial (RCT) with central randomization and core laboratory evaluation of angiography, subdivided into two treatment arms (SCS and iloprost) and two subgroups (rest pain and ulcer/gangrene). After the 15-day clinical efficacy evaluation, responder patients continued follow-up in their arm, while nonresponders could change arms or decline participation. The primary endpoint was 1-year limb salvage. Principal secondary endpoints were: survival rate; minor amputations and stump healing; ulcer healing; pain relief and analgesic intake; and predictive criteria for SCS treatment.

Results: The trial was stopped at $35.6 \%$ of the expected sample due to low accrual rate. Fiftytwo patients (55 legs) entered the study. At the 15-day efficacy evaluation, responders (reduced pain, no increase of ulcer area) comprised $74 \%$ of the SCS arm and $26 \%$ of the iloprost arm, $(P=0.003)$. Nine nonresponders in the iloprost arm underwent SCS implantation. Three severe adverse events (one fatal) were recorded in the iloprost arm and four in SCS treatments. Oneyear limb salvage rates in SCS, iloprost treatment, and iloprost plus SCS implantation (I-SCS) were $66.8 \%, 57.1 \%$, and $100 \%$, respectively $(P=0.09)$, and survival rates were $73.2 \%, 93.9 \%$, and $88.9 \%$, respectively $(P=0.45)$, confirming results of other studies that showed a trend toward better amputation-free salvage in the SCS group. The small number of recruited patients prevented statistical significance being reached. Pain reduction was obtained in $87 \%$ of SCS patients and $35 \%$ of those in the iloprost $\operatorname{arm}(P=0.001)$. Among the examined parameters, only the angiographic resistance index was an independent predictive value of good results after SCS implantation.

Discussion and conclusion: The SPINAL study is the first RCT comparing SCS and iloprost. Although incomplete, it evaluated a sample greater than those studied in three out of five available RCTs on SCS. However, the small sample size reduced the statistical power of the study, with possible type II errors. SCS was associated with a quick and more effective answer to pain, with better tolerability and better early results, than iloprost, but without significant 1-year limb salvage-rate improvement. Iloprost improved the 1-year survival in spite of adverse events, and, following these results, perhaps should be administered before other treatments. The results of this trial suggest that prostanoids and SCS are not alternative treatments: as prostanoids present many contraindications and side effects, SCS can be considered the complementary and consecutive treatment for patients who are no longer treatable with open or endovascular revascularizations, and an alternative treatment only in patients with contraindication to prostanoids. The association of iloprost and SCS seems to produce a synergic activity even in patients who had ineffective prostanoid treatment. These results should be confirmed by further investigations in a larger sample.

Keywords: critical limb ischemia, iloprost, spinal cord stimulation, peripheral arterial disease 


\section{Introduction}

Endovascular treatment of tibial and foot vessels offers more and more treatment opportunities for patients with critical limb ischemia (CLI), in whom femorodistal revascularization gives better long-term results for long lesions, ${ }^{1}$ classified as TASC D following the Trans-Atlantic Inter-Society Consensus Document on Management of Peripheral Arterial Disease (TASC). ${ }^{2}$ In some patients, however, the occlusion of distal vessels or the repeated thrombosis of previous treatments leads to the impossibility of further revascularization.

In cases in which revascularization is impossible, treatment of severe ischemia must aim for the reduction or disappearance of rest pain along with the preservation of limbs. Even though scientific evidence is lacking, both prostanoids and spinal cord stimulation (SCS) are considered to be valid therapies for these patients.

When the study was designed, there was no evidence for SCS; a subsequent Cochrane Review of six studies including patients with CLI concluded that spinal cord stimulation was significantly better than conservative treatment in improving limb salvage in patients without the option of vascular reconstruction. ${ }^{3}$ Notwithstanding, TASC II (published during the study) also concludes that there is low-level evidence for spinal cord stimulation to improve outcomes of patients with CLI, should revascularization not be possible. ${ }^{4}$ Equally, TASC II concludes that prostanoid treatment may also be of value; however, only a limited proportion of patients will respond to this treatment. ${ }^{4}$

The present study was designed to evaluate the clinical efficacy and safety of SCS plus medical treatment compared to prostacyclin plus medical treatment in patients with severe unrevascularizable ischemia of the lower limbs and to identify predictive parameters for a positive outcome.

The framework of the research is based on the selection criteria for SCS proposed by Gersbach et $\mathrm{al}^{5}$ and on the review of Spincemaille et al. ${ }^{6}$ These papers, in fact, showed four important results: 1) all patients with sitting transcutaneous oxygen tension $\left(\mathrm{TcPO}_{2}\right) \leq 20 \mathrm{mmHg}$ underwent amputation of the ischemic limb; 2) a difference between the supine and sitting $\mathrm{TcPO}_{2}$ baseline values $\left(\Delta \mathrm{TcPO}_{2}\right) \geq 15 \mathrm{mmHg}$ was related to $88 \%$ limb salvage; 3 ) a rise in $\mathrm{TcPO}_{2}$ after trial stimulation of at least $15 \%$ resulted in a limb salvage rate of $77 \%$ at 18 months $(P<0.01) ; 4)$ the outcome of patients with an initial $\mathrm{TcPO}_{2} \leq 10 \mathrm{mmHg}$ was significantly less favorable than those with a $\mathrm{TcPO}_{2}>10 \mathrm{mmHg}$.

\section{Methods}

The study was performed in eleven centers, as two centers did not enroll patients (see SPINAL study group in
Appendix section). All patients who participated in this study provided written informed consent. The study was approved by all the local hospital ethical committees. The study was sponsored by Medtronic Italia SpA (Sesto San Giovanni, MI, Italy) and randomization procedure was done by Quintiles SPA (Milano, Italy).

\section{Study design}

Patients affected by atherosclerotic or diabetic CLI with no chance of surgical revascularization, demonstrated by selective angiography and ultrasound, and/or after a failed attempt of endovascular revascularization, admitted to the eleven sites participating in the study, were considered for enrollment. Patients with arteritis or who were suitable for surgical revascularization but inoperable due to high surgical risk were excluded from the study. Patients with severe ischemia in both limbs were eligible if satisfying the inclusion criteria; the results regarding limb salvage or healing of the trophic lesions were assessed in each limb.

To avoid bias regarding the judgment for the possibility to perform a surgical revascularization in the prescreened patients, all angiograms were reviewed by the principal investigator (LP), who confirmed the eligibility of the patient and measured the angiographic resistance index (ARI), even if this had been calculated previously by the center responsible for the patient. This parameter was derived by the runoff score proposed by the International Society for Cardiovascular Surgery. ${ }^{7}$ All the arteries, beginning from the common iliac to the vessels of the foot, were evaluated according to the following scoring: patency $=0$; stenosis between $20 \%$ and $49 \%=1$; stenosis 50\%-99\%=2; short occlusion (less 50\% length) $=2.5$; and total occlusion $=3$. The arteries of the foot were scored as follows: full runoff $=0$; patent vessels without direct line from stenotic tibial vessels $=1$; incomplete plantar arch with direct flow from a tibial vessel $=2$; foot vessels open without any patent tibial artery $=2.5$; and no foot vessels $=3$.

\section{Inclusion criteria}

Severe ischemia of the lower limbs in atherosclerotic or diabetic patients with:

- persistent ischemic rest pain necessitating analgesics for at least 2 weeks;

- ankle systolic blood pressure $<50 \mathrm{mmHg}$ and/or finger systolic blood pressure $<30 \mathrm{mmHg}$ without lesions or with trophic lesions or gangrene of the feet or fingers;

- $\mathrm{TcPO}_{2}$ between $\geq 0 \mathrm{mmHg}$ and $\leq 30 \mathrm{mmHg}$ at base level, with horizontal limb with a $\Delta \mathrm{TcPO}_{2}$ (from supine to seated) $>15 \mathrm{mmHg}$; 
- revascularization impossible due to lack of out-flow;

- patients with failed surgical or endovascular treatment who could not be further treated;

- life expectancy of more than 1 year;

- signed informed consent form; and

- age $\geq 18$ years.

\section{Exclusion criteria}

Patients who met the following criteria were excluded from the study:

- peripheral arterial occlusion due to arteritis;

- baseline $\mathrm{TcPO}_{2}>30 \mathrm{mmHg}$ with horizontal limb or with $\Delta \mathrm{TcPO}_{2}$ (from supine to seated) $<15 \mathrm{mmHg}$;

- gangrene extending to the forefoot;

- life expectancy $<1$ year;

- end-stage renal failure;

- cirrhosis or cancer;

- myocardial infarction or stroke in the previous 6 months;

- heart failure (New York Heart Association class >1);

- unstable angina;

- hyperkinetic ventricular arrhythmia;

- severe arterial hypertension (systolic blood pressure $>180 \mathrm{mmHg}$, diastolic blood pressure $>110 \mathrm{mmHg}$ );

- severe hypotension (systolic blood pressure $<90 \mathrm{mmHg}$ );

- hemorrhagic diathesis or pathology with risk of hemorrhage (active peptic ulcer, cerebral hemorrhage, recent traumas $<1$ month before);

- thrombocytopenia (platelets $<80,000 / \mathrm{mm}^{3}$ ) or thrombocytosis (platelets $>500,000 / \mathrm{mm}^{3}$ );

- serious psychological problems and/or inability to manage the stimulator;

- spine modification that could make lead positioning impossible;

- allergy to metal;

- contraindications to prostanoid therapy;

- treatment with prostanoid in the preceding 6 months;

- pregnancy;

- inclusion in other pharmacological studies in the preceding 30 days; and

- any condition that, in the opinion of those conducting the study, could make the patient unable to complete the study, increase the risk to the patient, or make it impossible to achieve the objectives of the study.

\section{Randomization}

After the centralized review of the angiographs, the randomization to SCS or drug, stratified by Leriche-Fontaine stage
(III or IV), was made centrally and notified to the treatment center within 24 hours.

Patients allocated to the SCS arm underwent a test screening, for a maximum of 2 weeks, with a Pisces-Quad ${ }^{\circledR}$ LZ lead (3890; Medtronic, Inc., Minneapolis, MN, USA).

Patients assigned to the iloprost arm underwent endovenous infusion with iloprost at a dose of $0.5-1.5 \mathrm{ng} / \mathrm{kg} /$ minute (at the maximum individual tolerated dose ascertained in the first 2-3 days) for 16 hours/day for 7 days.

\section{Clinical efficacy evaluation}

In cases where CLI does not improve quickly, the limb deteriorates towards amputation, for this reason the efficacy of a treatment should be judged early, at $15 \pm 3$ days after randomization, at the patients follow-up visit. Patients who satisfied the following criteria were classified as responders:

- reduction of the visual analog scale (VAS) value of at least $50 \%$ compared with the value at enrollment;

- no increase in the size of the trophic lesions; and

- no major lower-limb amputation.

Patient responders in the SCS arm underwent permanent SCS implantation (Itrel ${ }^{\circledR} 3$ [code 7425 or $7427 \mathrm{~V}$ or 7427 ]; Medtronic, Inc.); nonresponders had the lead explanted and could receive iloprost treatment or other standard medical treatment.

Patient responders in the iloprost arm could repeat the iloprost treatment after the second month of follow-up, if results were deteriorating. Patient nonresponders in the iloprost arm could also switch over the therapy and receive an SCS implant test evaluation.

\section{Concomitant treatments}

Antiplatelet (aspirin 100-375 mg and/or ticlopidine $250 \mathrm{mg}$ twice a day) or oral anticoagulant, antihypertensive, lipidlowering drugs, and all the standard treatments for systemic diseases were maintained, except for a temporary replacement of the ticlopidine with aspirin in patients assigned to SCS in order to avoid spinal cord hemorrhage. The use of pentoxifylline and naftidrofuryl was allowed. Cilostazol was not available in Italy during the study; moreover, it is not indicated in the treatment of CLI. Oral and transcutaneous analgesics were administered and stabilized before enrollment and maintained until the first follow-up visit; subsequently, they were reduced or stopped after assessing a clinical improvement or a pain reduction at the follow-up evaluation. All the admitted changes of medical treatment were recorded in the case report form. Epidural treatment with analgesic and anesthetic drugs was not allowed. 
Hyperbaric oxygen therapy was admitted in patients with ulcer infection. Heparin treatment was admitted in patients on warfarin who were entered into the SCS arm to allow lead implantation. Specific antibiotic therapy, hydration, and ulcer debridement and medications were also recommended.

Pain treatment was adjusted before inclusion, as pain evaluation using the VAS was one of the criteria to evaluate early efficacy. Patients with moderate pain had 24 hours wash-out of treatment before the VAS measure.

\section{Assessments}

The following parameters were evaluated at baseline: demographics, clinical history and physical evaluation, angiography, and color-Doppler. Parameters evaluated at all visits (baseline and follow-up [15 \pm 3 days and 2, 6, and 12 months]) were: ankle-brachial index (ABI); supine and pending $\mathrm{TcPO}_{2}$, delta $\mathrm{TcPCO}_{2}$; laser Doppler (optional); number of ulcers and total area; pain (VAS); quality of life (12-Item Short Form Survey $\left.\left[\mathrm{SF}-12^{\circledR}\right]\right)$; performance in activities of daily living, using the Barthel Index; pharmacological treatment; amputation level; pharmaco economic evaluation; stimulation parameters (only in the SCS arm); and adverse events.

Parameters measured for safety (at baseline and follow-up

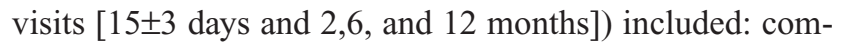
plete blood count; prothrombin time/international normalized ratio; activated partial thromboplastin time; glycemia; serum creatinine; fibrinogen; liver transaminases (aspartate transaminase/alanine transaminase); electrocardiography; and chest X-ray (only before enrollment).

\section{Endpoints}

The primary endpoint was the limb salvage rate at 12 months follow-up. Secondary endpoints were: survival rate; minor amputations and stump healing; ulcer healing; pain relief and analgesic intake; quality of life and disability status; relationship between stimulation parameters and results; economic evaluation (direct and indirect costs); and predictive criteria regarding SCS outcome.

The protocol provided an ad interim analysis of the percentage of limb salvage after 2 months of follow-up at the enrollment of at least $25 \%$ of the expected patients.

\section{Sample size calculation and statistical analysis}

The sample size was calculated for the primary variable, percentage of limb salvage at 12 months follow-up, with a significance level $\alpha=0.05$, statistical power $(1-\beta)=0.80$, two-tailed test; the expected percentage of limb salvage with iloprost was $65 \%$, and expected percentage of limb salvage with SCS was $85 \%$. On this basis, the sample size was established as 73 patients for each treatment group.

The intent-to-treat patient set consisted of all patients as they were randomized into the study (SCS or iloprost). Patients who underwent a group inversion (ie, they had initially been randomized to the SCS arm, but in the course of the study had switched to the iloprost arm, or vice versa) were included and analyzed in two different groups: SCS + iloprost or iloprost + SCS, with limb salvage and survival evaluated separately from the two randomized arms (pertreatment results).

Data were collected and reviewed with Microsoft Excel and Microsoft Access (Microsoft Corporation, Redmond, WA, USA). Statistical analysis was performed with SPSS software (v 12.0; IBM Corporation, Armonk, NY, USA) and Stata/SE for Windows (v 11.0; StataCorp LP, College Station, TX, USA). Descriptive statistics were reported as mean and standard deviation for normally distributed continuous variables, or median with 25 th to 75 th interquartile range in the case of skewed distribution. Categorical variables were expressed as absolute and relative frequencies. Normality was assessed by means of Kolmogorov-Smirnov test. Continuous variables included age at enrollment, time from onset of ischemia, angiographic indices, $\mathrm{TcPO}_{2}$, VAS value, blood pressure, and $\mathrm{ABI}$.

Differences between groups in categorical variables were evaluated by means of the $\chi^{2}$ test or Fisher's exact test, when appropriate. Statistical comparisons of continuous variables between groups were performed by Student's $t$-test or nonparametric test (Mann-Whitney $U$-test or Wilcoxon signed-rank test) for normal and non-normal distributions, respectively. Mortality and limb salvage were evaluated by using Kaplan-Meier curves. The distributions of the groups were compared by a logrank test.

The General Linear Model (GLM) for repeated measures or the Friedman test (for skewed distribution) was used to assess variations in $\mathrm{TcPO}_{2}$ and VAS values over time in the two groups of patients.

Independent predictors of SCS success (defined as conclusion of the study without major amputations) were detected by means of a univariable and then multivariable logistic model that included all the variables showing a significant influence in the univariate analysis. Goodness of fit of each model was assessed by HosmerLemeshow test. 
All two-tailed $P$-values $<0.05$ were considered statistically significant.

\section{Results}

The start of enrollment was delayed in many centers due to the time required to obtain the ethical committee approval and to fulfill other administrative requirements (ie, study agreement). Moreover, the progress in endovascular revascularization surgery increased the number of these procedures with a significant decrease in the recruitment velocity in the trial, which presented a danger of reduction of the quality of data. The steering committee decided to interrupt the study and to proceed with the ad interim analysis in order to collect the results of a 1-year follow-up on the treated patients before publishing them, although, in the meantime, only $35.6 \%$ of the expected sample size had been enrolled.

Between July 2003 and June 2007, 55 patients were assessed for eligibility, but three were excluded: two declined to participate and one died before randomization. Overall, 52 patients (males $34,65 \%$, mean age $75.1 \pm 8.7$ years) were randomized according to the study procedure: 25 (48\%) to the SCS arm and 27 to the iloprost group (Figure 1).
Two patients in the SCS group and one in the iloprost group had both legs affected by similar lesions, so we evaluated 52 patients and 55 legs -27 in the SCS group and 28 in the iloprost group. Four patients in each group had had previous failed revascularizations. Two patients in each group had had a contralateral leg amputated; one in each group had calcaneal ulcers moreover one in the SCS group had a plantar ulcer. Demographics and clinical data are reported in Table 1; no significant difference emerged between the two groups.

In Table 2, we report the ARIs measured at baseline; no statistical difference was found between the two arms. Table 3 shows macro- and microcirculatory parameters, pain evaluation (VAS), quality of life, and Barthel Index measured at baseline; no significant differences were observed in the two groups.

\section{Early clinical efficacy}

In the iloprost group, three patients experienced severe adverse events, which led to immediate treatment interruption in two cases and death in the other. Moreover, one patient refused to complete the 7 days of treatment after a few days because of personal problems. One patient in the SCS group experienced severe adverse events, which led to interruption
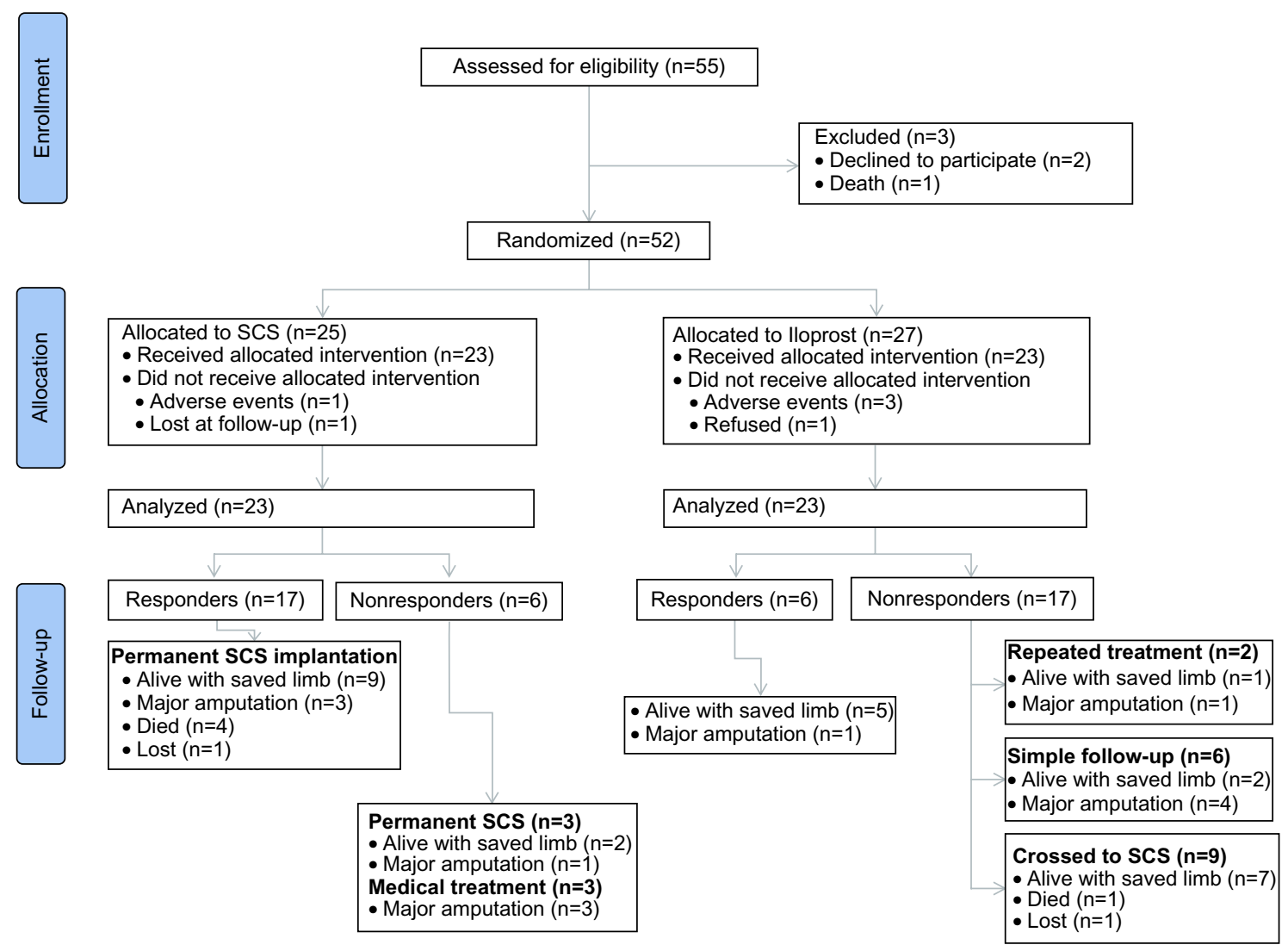

Figure I Flowchart of primary treatment, early results, and treatment at follow-up. Abbreviation: SCS, spinal cord stimulation. 
Table I Demographics, risk factors, and pretreatment clinical evaluation

\begin{tabular}{|c|c|c|c|}
\hline Parameter & SCS & Iloprost & $P$-value \\
\hline Patients (target legs), $\mathrm{n}$ & $25(27)$ & $27(28)$ & \\
\hline Sex M:F, n (M \%, F \%) & $16: 9(64,36)$ & $18: 9(67,33)$ & 1.000 \\
\hline Age, years, mean $\pm S D$ & $73.9 \pm 9.2$ & $76.1 \pm 8.3$ & $0.207^{a}$ \\
\hline Diabetes, n (\%) & $12(48)$ & $10(37)$ & $0.575^{b}$ \\
\hline Type I (IDDM), n (\%) & $I(8)$ & $\mathrm{I}(10)$ & $1.000^{\mathrm{b}}$ \\
\hline Type II (NIDDM), n (\%) & $11(92)$ & $9(90)$ & \\
\hline Hypertension, n (\%) & $16(64)$ & $23(85)$ & $0.112^{b}$ \\
\hline Dyslipidemia, n (\%) & $8(32)$ & $8(30)$ & $1.000^{\mathrm{b}}$ \\
\hline \multicolumn{4}{|l|}{ Smoking habits } \\
\hline Smokers, n (\%) & $3(16)$ & $6(29)$ & $0.416^{c}$ \\
\hline Nonsmokers, n (\%) & $9(47)$ & $6(29)$ & \\
\hline Former smokers, n (\%) & $7(37)$ & $9(43)$ & \\
\hline Previous myocardial & $8(32)$ & $6(22)$ & $0.536^{\mathrm{b}}$ \\
\hline infarction, n (\%) & & & \\
\hline Previous stroke, n (\%) & $2(8)$ & $3(11)$ & $1.000^{\mathrm{b}}$ \\
\hline $\begin{array}{l}\text { Persistence of ischemic } \\
\text { symptoms, months, mean } \\
\text { (range) }\end{array}$ & $1.7(0.7-6.4)$ & $2.8(0.7-9.9)$ & $0.828^{\mathrm{a}}$ \\
\hline Serum creatinine, mean $\pm S D$ & $\begin{array}{l}1.2 \pm 0.5 \\
\mathrm{mg} / \mathrm{dL}\end{array}$ & $\begin{array}{l}1.2 \pm 0.4 \\
\mathrm{mg} / \mathrm{dL}\end{array}$ & $\begin{array}{l}0.695 \\
\mathrm{mg} / \mathrm{dL}^{\mathrm{a}}\end{array}$ \\
\hline \multicolumn{4}{|c|}{ Clinical stage (Leriche-Fontaine classification) } \\
\hline Rest pain (stage III), n (\%) & $10(40)$ & $12(44)$ & $0.785^{b}$ \\
\hline $\begin{array}{l}\text { Ulcers or gangrene } \\
\text { (stage IV), } \mathrm{n}(\%)\end{array}$ & $15(60)$ & $15(56)$ & \\
\hline $\begin{array}{l}\text { Previous minor amputation } \\
\text { in the target leg, } \mathrm{n}(\%)\end{array}$ & $3(\mathrm{II})$ & $3(I I)$ & $1.000^{\mathrm{b}}$ \\
\hline $\begin{array}{l}\text { Gangrene in the target } \\
\text { leg, } n(\%)\end{array}$ & $5(19)$ & $3(I I)$ & $0.458^{\mathrm{b}}$ \\
\hline $\begin{array}{l}\text { Total ulcer area in the } \\
\text { target leg, } \mathrm{cm}^{2} \text {, mean } \pm S D\end{array}$ & $2.3 \pm 1.6$ & $1.9 \pm 1.2$ & $0.463^{d}$ \\
\hline
\end{tabular}

Notes: ${ }^{a} M a n n-W h i t n e y ~ n o n p a r a m e t r i c ~ U$-test; 'Fisher's exact test; ' $\chi{ }^{2}$ test; 'student's $t$-test for independent samples.

Abbreviations: F, female; IDDM, insulin-dependent diabetes mellitus; M, male; NIDDM, noninsulin-dependent diabetes mellitus; SCS, spinal cord stimulation; SD, standard deviation.

of the treatment, and another was lost to follow-up. Overall, 46 patients were evaluated at the follow-up visit at $15 \pm 3$ days post-randomization: 23/25 (92\%) in the SCS arm and 23/27 $(85 \%)$ in the iloprost arm.

Table 2 Angiographic resistance index calculated for proximal tract, infrainguinal tract, below-the knee tract, foot arteries, and whole leg

\begin{tabular}{lccc}
\hline Evaluated arteries & \multicolumn{1}{l}{$\begin{array}{l}\text { SCS } \\
(\mathbf{N}=\mathbf{2 7})\end{array}$} & $\begin{array}{l}\text { Iloprost } \\
(\mathbf{N}=\mathbf{2 8})\end{array}$ & P-value $^{\mathbf{a}}$ \\
\hline Common iliac artery & $0.0 \pm 0.0$ & $0.1 \pm 0.6$ & 0.317 \\
External iliac artery & $0.0 \pm 0.0$ & $0.2 \pm 0.6$ & 0.153 \\
Common femoral artery & $0.0 \pm 0.0$ & $0.2 \pm 0.6$ & 0.153 \\
SFA - foot arteries & $16.6 \pm 5.0$ & $15.9 \pm 4.8$ & 0.410 \\
Tibial arteries & $7.9 \pm 1.8$ & $7.9 \pm 1.8$ & 0.565 \\
Foot arteries & $2.7 \pm 0.9$ & $2.6 \pm 0.6$ & 0.772 \\
Global angiographic & $16.9 \pm 5.2$ & $16.4 \pm 5.7$ & 0.345 \\
resistance index & & &
\end{tabular}

Notes: Data are presented as mean \pm standard deviation. aMann-Whitney nonparametric U-test.

Abbreviations: SCS, spinal cord stimulation; SFA, superficial femoral artery.
Table 3 Vascular parameters, pain evaluation, and quality of life and activities of daily living performances measured at randomization

\begin{tabular}{llll}
\hline Parameter & SCS & Iloprost & P-value \\
\hline Supine $\mathrm{TcPO}_{2}$ target leg, mmHg & $12.0 \pm 9.7$ & $11.0 \pm 8.9$ & $0.798^{\mathrm{a}}$ \\
Sitting $\mathrm{TcPO}_{2}$ target leg, mmHg & $34.5 \pm 11.8$ & $36.0 \pm 11.6$ & $0.727^{\mathrm{a}}$ \\
Ankle systolic BP target leg & $78.0 \pm 68.7$ & $55.3 \pm 39.5$ & $0.882^{\mathrm{a}}$ \\
$\mathrm{ABI}$ target leg & $0.34 \pm 0.17$ & $0.34 \pm 0.15$ & $0.994^{\mathrm{b}}$ \\
$\mathrm{ABI}$ contralateral leg & $0.64 \pm 0.37$ & $0.72 \pm 0.30$ & $0.769^{\mathrm{b}}$ \\
Pain evaluation (VAS 0-100) & $80.9 \pm 16.7$ & $81.4 \pm 12.7$ & $0.808^{\mathrm{a}}$ \\
Barthel Index (0-I00) & $79.2 \pm 25.8$ & $71.9 \pm 30.6$ & $0.252^{\mathrm{a}}$ \\
SF-I2 Physical Component Score & $29.3 \pm 7.3$ & $29.3 \pm 6.4$ & $0.877^{\mathrm{a}}$ \\
SF-I2 Mental Component Score & $34.6 \pm 13.1$ & $35.2 \pm 13.0$ & $0.926^{\mathrm{a}}$ \\
\hline
\end{tabular}

Notes: Data are presented as mean \pm standard deviation. aMann-Whitney nonparametric U-test; 'Student's t-test.

Abbreviations: $A B I$, ankle-brachial index; BP, blood pressure; SCS, spinal cord stimulation; SF-12, I2-Item Short Form Survey; $\mathrm{TcPO}_{2}$, transcutaneous oxygen tension; VAS, visual analog scale.

Overall, 17/23 (74\%) in the SCS group and 6/23 (26\%) in the iloprost group were considered responders (VAS reduction $\geq 50 \%$, no major lower-limb amputation and no increase in the size of the trophic lesions $)(P=0.003)$. Even considering the drop-outs, the difference is between the two arms is still statistically significant $(P=0.002)$. Regarding the target legs, $19 / 25(76 \%)$ in the SCS sample responded to treatment versus $6 / 24(25 \%)$ in the iloprost group $(P<0.001)$.

Nine of 17 patients randomized in the iloprost group and classified as nonresponders to that therapy at the follow-up visit $15 \pm 3$ days post-randomization underwent SCS implantation (iloprost + SCS group [I-SCS]): four after $15 \pm 3$ days, two after 1 month, and three after 2 months. Two patients repeated the treatment: one underwent major amputation at 2 months and one ended the follow-up with limb saved (Figure 1).

Only one patient in the SCS arm underwent a short concomitant treatment with PGI1 at 4 months of follow-up for a worsening of symptoms, which promptly improved. He was alive with limb saved at 12 months.

\section{Limb salvage}

Statistical analysis was performed on 55 target limbs (52 patients). The mean follow-up for the iloprost arm was $8.8 \pm 5.6$ months (range $0.03-17.10$ ) and $7.8 \pm 4.6$ months (range 0.46-13.41) for the SCS arm. Overall, 13 patients (24\%) underwent major limb amputation: seven (26\%) in the SCS arm and six (21\%) in the iloprost arm $(P=0.758)$; of these, eight amputations were between 2 months, four at 6 months, and one at 1 year. There was no statistical difference between the two groups (logrank test, $P=0.720$ ). The probability of limb salvage based on the intention-to-treat basis at 2 months 
was $88.4 \% \pm 6.3 \%$ for the SCS arm and $87.5 \% \pm 6.8 \%$ for the iloprost arm (not statistically different).

Causes of early amputation in the SCS arm were progression of CLI due to inefficacy in two cases and to lead infection following explant in another; causes of late amputations were a microcirculatory deterioration after acute respiratory failure at more than 6 months in one patient and worsening of the arterial disease in another three cases.

In the iloprost arm, we observed two early amputations due to inefficacy and two amputations at 2 months and one at 6 months all in nonresponders to treatment due to progression of limb ischemia; the last amputation was performed in a responder patient who had late deterioration of his general condition.

Besides evaluating limb salvage linked to the first treatment, we analyzed the limb salvage rate in the three subgroups (Figure 2). The probabilities of avoiding a major amputation at 12 months were $66.8 \pm 10.9$ after SCS, $57.1 \pm 13.2$ after iloprost treatment, and $100.0 \pm 0.0$ after combined treatment (iloprost + SCS). There was a trend toward significance among the three curves (logrank test, $P=0.093)$; comparing the groups, we did not find any difference between iloprost and SCS $(P=0.453)$; SCS versus I-SCS showed a trend toward significance $(P=0.065)$, while the difference between iloprost and I-SCS was significant $(P=0.028)$.

Five (33.3\%) of the 15 patients with ulcers or gangrene in the SCS arm and 2/15 (13.3\%) in the iloprost arm underwent minor amputations as a consequence of their lesions.

\section{Survival}

Seven patients died, including two in the iloprost arm: one from acute myocardial infarction (probably related to treatment) and one from suicide. Among the five patients in the SCS arm who died, one who experienced an adverse event (skin infection which needed lead explant) died after a major amputation, while the others died from concomitant diseases between 2 and 6 months after the treatment for senile decay (one case), heart failure (two cases), and bronchopneumonia (one case).

The 1-year survival rate was not statistically significant (logrank test, $P=0.216$ ) after iloprost treatment ( $91.3 \% \pm 5.9 \%$ ) or SCS $(73.2 \% \pm 10.5 \%)$. Also, survivorship evaluated in the three subgroups (Figure 3 ) showed not significant differences (logrank test, $P=0.456$ ).

\section{Survival with saved limb}

At a mean follow-up of 8.8 \pm 5.6 months (range 0.03-17.10) for patients randomized into the iloprost group and of 7.8 \pm 4.6 months (range 0.46-13.41) for those in the SCS group, we observed, overall, 20 events (36\%): 12 (44\%) in the SCS arm and eight (29\%) in the iloprost arm $(P=0.269)$.

The probability of surviving without major amputation at 12 months was $50.7 \% \pm 10.4$ after SCS and $67.7 \% \pm 9.4 \%$ after iloprost treatment (not significant difference).

Subdividing results in the three subgroups, including the I-SCS treatment, the probabilities to avoid combined major endpoints were: $50.7 \pm 10.4$ for SCS, $53.7 \pm 12.9$ for iloprost, and $90.0 \pm 9.5$ after I-SCS treatment. Overall results

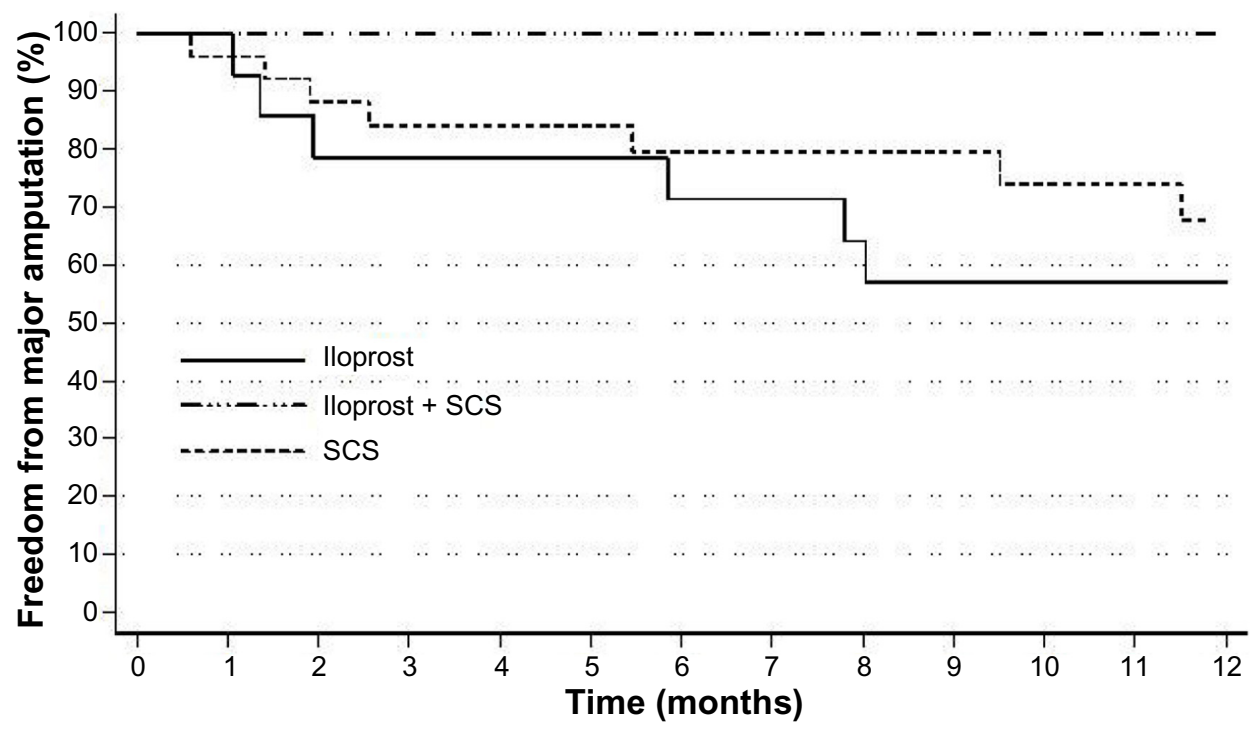

Figure 2 Limb salvage rate in the three subgroups including the iloprost + SCS treatment.

Note: $P=0.093$, logrank test.

Abbreviation: SCS, spinal cord stimulation. 


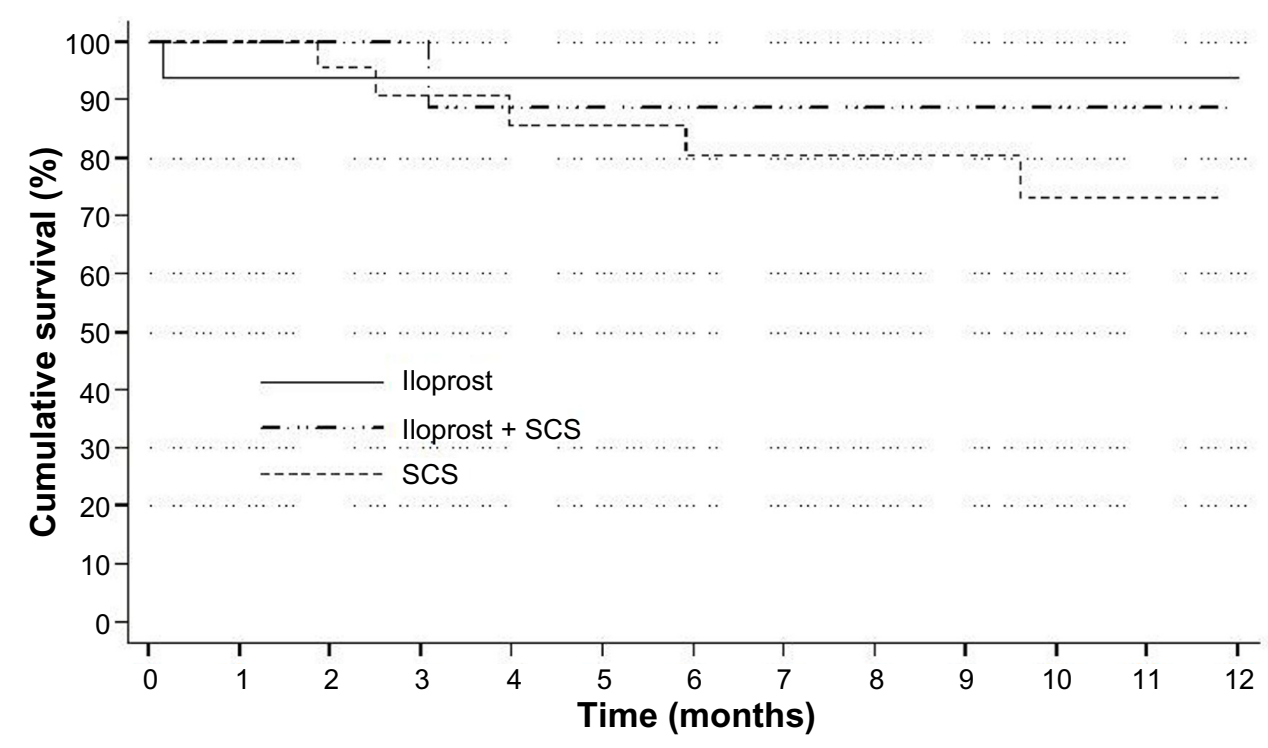

Figure 3 Cumulative survival in the three subgroups including the iloprost + SCS treatment. Note: $P=0.456$, logrank test.

Abbreviation: SCS, spinal cord stimulation.

of treatments are represented by survivorship with saved limbs in Figure 4.

Comparing the treatments, we did not find any difference between iloprost and SCS $(P=0.936)$, while the differences in outcomes between single and combined treatment, although not significant, showed a trend: SCS versus iloprost + SCS $(P=0.055)$ and iloprost versus iloprost + SCS $(P=0.071)$.

Results from the end of follow-up are summarized in Table 4.

\section{Pain relief}

Results about pain showed a significant difference between the two groups at the $15 \pm 3$ days follow-up visit, with a pain reduction greater than $50 \%$ in $87 \%$ of patients in the SCS group versus $35 \%$ of those in the iloprost group $(P=0.001)$.

The analysis of changes of mean values was not possible, as not all the patients (nonresponders, amputees, and dropouts) completed all the evaluation; it was therefore difficult to show a trend. In the iloprost group, all patients alive with limb

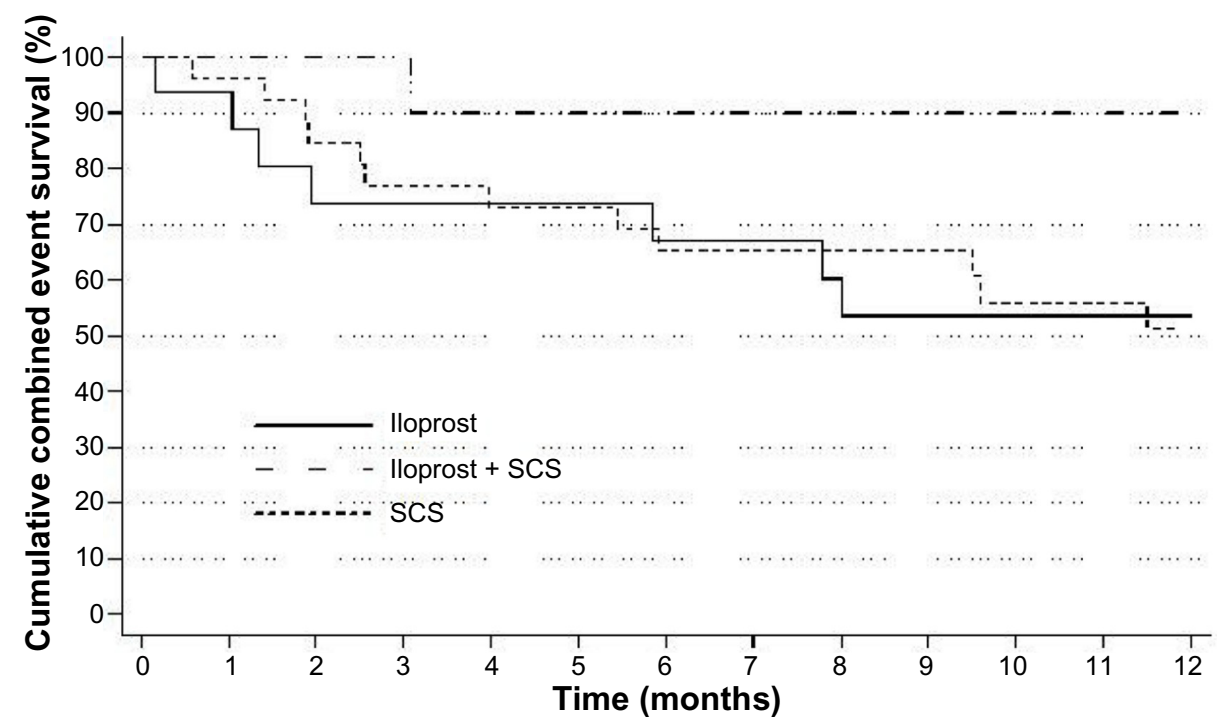

Figure 4 Cumulative survival with saved limb in the three subgroups including the SCS implantation after lloprost treatment (I-SCS).

Note: $P=0.150$, logrank test.

Abbreviation: SCS, spinal cord stimulation. 
Table 4 Crude results at the end of follow-up

\begin{tabular}{llll}
\hline Crude results & $\begin{array}{l}\text { SCS } \\
(\mathbf{N}=\mathbf{2 5})\end{array}$ & $\begin{array}{l}\text { Iloprost } \\
\mathbf{( N = 1 8 )}\end{array}$ & $\begin{array}{l}\text { Iloprost + SCS } \\
(\mathbf{N}=9)\end{array}$ \\
\hline Alive with leg saved & II (44) & $8(44)$ & $7(78)$ \\
Alive amputated & $7(28)$ & $6(33)$ & 0 \\
Died & $5(20)$ & $\mathrm{I}(6)$ & $\mathrm{I}(1 \mathrm{I})$ \\
Censored & $2(8)$ & $3(\mathrm{I})$ & $\mathrm{I}(\mathrm{II})$ \\
\hline
\end{tabular}

Notes: Data are presented as $n(\%) . P=0.333, \chi^{2}$ test.

Abbreviation: SCS, spinal cord stimulation.

saved at the end of follow-up had an impressive pain reduction from $87.5 \pm 13.2$ of mean baseline VAS value to $20 \pm 13.6$ at 1 year. Patients who underwent amputation VAS changed from $75.8 \pm 16.8$ at baseline to $75 \pm 27.3$ at the evaluation at 15 days (clinical efficacy). In patients who repeated iloprost treatment, VAS value decreased again after the second treatment.

In the SCS group, all patients alive with limb saved had a progressive pain release from a mean value of $80.5 \pm 11.6$ at baseline to $33.5 \pm 21.1$ at the 15-day evaluation, with further decreases to $22 \pm 26.2$ at 2 months, $18.3 \pm 19.5$ at 6 months, and $7.2 \pm 10.9$ in the final evaluation at 12 months. Also in this group, patients who underwent amputation had no change or a worsening of VAS values after the improvement recorded at the 15-day evaluation. All patients who died in the follow-up had reported an impressive pain reduction or complete relief in the intermediate evaluations.

In the group of patients who underwent sequential iloprost + SCS treatments, seven had a VAS score decrease of about 50\% after the SCS implantation, while two had only a slight change in VAS scores, of whom one was lost a follow-up and one reached 12 month follow-up alive without amputation.

Mean values of VAS in patients who completed all evaluation at 1-year follow-up are reported in Table 5. All groups experienced a significant pain reduction; all patients reduced or stopped the intake of painkillers.

SCS gave a quicker and greater pain reduction, improving faster their quality of life.

\section{Safety of the treatment}

Regarding treatment safety, we recorded a mild, not significant, increase of serum creatinine in the iloprost group (from $1.19 \mathrm{mg} / \mathrm{dL} \pm 0.41 \mathrm{mg} / \mathrm{dL}$ to $1.27 \mathrm{mg} / \mathrm{dL} \pm 0.47 \mathrm{mg} / \mathrm{dL}$; $P=0.347$ ) and a significant decrease of serum creatinine in the SCS group (from $1.27 \mathrm{mg} / \mathrm{dL} \pm 0.58 \mathrm{mg} / \mathrm{dL}$ to $1.12 \mathrm{mg} / \mathrm{dL}$ $\pm 0.42 \mathrm{mg} / \mathrm{dL} ; P=0.048)$, likely due to a greater reduction of painkiller in this arm.

Severe and moderate adverse events that occurred during the study are reported in Table 6. These comprised seven severe (four in the SCS arm and three in the iloprost arm) and three moderate (iloprost arm) events. We did not detect local or systemic bleeding complications.

Systemic severe complications led to discontinuation of iloprost treatment, notwithstanding the exclusion from treatment of patients with clear systemic contraindication to prostanoids. Five patients in the iloprost group did not tolerate the treatment, which was subsequently ended before the 7 days decided in the protocol. Of these, two were considered dropouts and three, who actually had an almost complete treatment, were considered nonresponders. Another dropout in the iloprost group was due to death from myocardial infarction.

In the SCS group, three patients experienced an infection (two early, with one dropout due to death; and one late at about 3 months post-operative) and one patient experienced late respiratory failure not related to treatment. Overall, six patients dropped out of the study. Moreover, we recorded a total of 94 other, minor adverse events related to iloprost treatment (classical side effects).

\section{Predictive criteria of successful SCS}

Logistic regression analysis was performed in the 22 patients in the SCS arm who remained in the study for at least 2 months after SCS implantation. Of these, 15 (68\%) improved (eleven alive without major amputation at the end of follow-up, however three later died, and one was lost to follow-up), and seven underwent limb amputation. In univariate analysis, only the ARI of the foot (with the limits of the small sample) resulted in an independent predictive value of a good result after SCS implantation, as the probability of amputation increased two times for each ARI point increased, while the presence of a gangrene nearly reached significance for decreasing the probability of saving the limb (Table 7).

Table 5 Mean visual analog scale values in patients who had all the planned assessments at follow-up

\begin{tabular}{lllllll}
\hline Group & Baseline & I5 days & 2 months & 6 months & I year & P-value \\
\hline SCS $(\mathrm{N}=13)$ & $84.2 \pm 10.4$ & $35.4 \pm 18.0$ & $22.7 \pm 23.8$ & $33.3 \pm 31.8$ & $15.4 \pm 21.7$ & $<0.00 \mathrm{I}^{\mathrm{a}}$ \\
Iloprost $(\mathrm{N}=5)$ & $86.0 \pm 15.2$ & $40.0 \pm 7.9$ & $38.0 \pm 17.9$ & $30.2 \pm 29.6$ & $32.0 \pm 37.0$ & $0.009^{\mathrm{b}}$ \\
I-SCS $(\mathrm{N}=8)$ & $86.9 \pm 4.6$ & $79.4 \pm 20.4$ & $32.5 \pm 16.7$ & $23.8 \pm 26.7$ & $23.8 \pm 25.5$ & $0.00 \mathrm{I}^{\mathrm{a}}$ \\
\hline
\end{tabular}

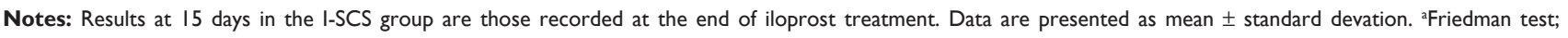
bgeneralized linear model for repeated measures.

Abbreviations: I-SCS, lloprost + SCS implantation; SCS, spinal cord stimulation. 
Table 6 Adverse events recorded

\begin{tabular}{|c|c|c|c|c|c|c|}
\hline Event & Severity & Group & Time & Event treatment & $\begin{array}{l}\text { Relationship with } \\
\text { principal treatment }\end{array}$ & Final results \\
\hline SCS pocket infection & Severe & SCS & 8 days & $\begin{array}{l}\text { Hospitalization - lead } \\
\text { explant }\end{array}$ & Related & $\begin{array}{l}\text { Died of senile decay } \\
\text { I month later }\end{array}$ \\
\hline Lead infection & Severe & SCS & 10 days & $\begin{array}{l}\text { Hospitalization - lead } \\
\text { explant }\end{array}$ & Related & $\begin{array}{l}\text { Major amputation } 5 \text { days } \\
\text { after }\end{array}$ \\
\hline $\begin{array}{l}\text { Late infection of } \\
\text { SCS }\end{array}$ & Severe & SCS & 105 days & $\begin{array}{l}\text { Hospitalization - explant } \\
\text { and new SCS implant }\end{array}$ & Related & $\begin{array}{l}\text { Alive with leg saved } \\
\text { at the end of follow-up }\end{array}$ \\
\hline $\begin{array}{l}\text { Acute respiratory } \\
\text { failure }\end{array}$ & Severe & SCS & 207 days & Hospitalization & Not related & $\begin{array}{l}\text { Microcirculatory } \\
\text { deterioration, leg amputation } \\
\text { at } 235 \text { days of follow-up }\end{array}$ \\
\hline $\begin{array}{l}\text { Acute myocardial } \\
\text { infarction }\end{array}$ & Severe & lloprost & 5 days & $\begin{array}{l}\text { Treatment suspension and } \\
\text { cardiopulmonary resuscitation }\end{array}$ & Probably related & $\begin{array}{l}\text { Died of acute myocardial } \\
\text { infarction }\end{array}$ \\
\hline Heart failure & Severe & lloprost & 2 days & $\begin{array}{l}\text { Iloprost suspension and SCS } \\
\text { implantation }\end{array}$ & Possibly related & $\begin{array}{l}\text { Alive without amputation at } \\
\text { the end of follow-up }\end{array}$ \\
\hline $\begin{array}{l}\text { Intolerance to } \\
\text { treatment }\end{array}$ & Moderate & lloprost & 3 days & $\begin{array}{l}\text { lloprost suspension and SCS } \\
\text { implantation }\end{array}$ & Related & $\begin{array}{l}\text { Alive without amputation at } \\
\text { the end of follow-up }\end{array}$ \\
\hline Severe bradycardia & Severe & lloprost & 5 days & Treatment suspension & Probably related & $\begin{array}{l}\text { Major amputation at } \\
6 \text { months of follow-up }\end{array}$ \\
\hline $\begin{array}{l}\text { Intolerance to } \\
\text { treatment, tachycardia }\end{array}$ & Moderate & lloprost & 2 days & Treatment suspension & Probably related & Lost to follow-up; censored \\
\hline $\begin{array}{l}\text { Intolerance to } \\
\text { treatment }\end{array}$ & Moderate & lloprost & 3 days & Treatment suspension & $\begin{array}{l}\text { Probably } \\
\text { related }\end{array}$ & Lost to follow-up; censored \\
\hline
\end{tabular}

Abbreviation: SCS, spinal cord stimulation.

In multivariate analysis, even the ARI of foot arteries did not reach significance (odds ratio $=0.01,95 \%$ confidence interval: $0.00-1.05, P=0.052)$; the presence of gangrene lost its trend of significance (odds ratio $=0.12,95 \%$ confidence interval $=0.01-2.52, P=0.173$ ).

Table 7 Univariate analysis of freedom from amputation after spinal cord stimulation

\begin{tabular}{|c|c|c|c|}
\hline Parameter & OR & $\mathrm{Cl}(95 \%)$ & $P$-value \\
\hline Age & 1.01 & $0.91-1.11$ & 0.895 \\
\hline Sex (male) & 0.60 & $0.09-4.17$ & 0.605 \\
\hline Diabetes & 0.50 & $0.08-3.08$ & 0.455 \\
\hline Hypertension & 2.06 & $0.31-13.57$ & 0.451 \\
\hline Dyslipidemia & 1.67 & $0.24-11.57$ & 0.605 \\
\hline Smoking habits & 1.00 & $0.14-7.10$ & 1.000 \\
\hline Previous myocardial infarction & 0.33 & $0.05-2.37$ & 0.272 \\
\hline Persistence of ischemic symptoms, days & 1.00 & $1.00-1.01$ & 0.914 \\
\hline Serum creatinine & 3.55 & $0.20-61.76$ & 0.385 \\
\hline Leriche-Fontaine stage IV & 0.46 & $0.07-3.14$ & 0.426 \\
\hline Ankle systolic blood pressure, target leg & 1.01 & $0.96-1.06$ & 0.754 \\
\hline Supine $\mathrm{TcPO}_{2}$ target leg, $\mathrm{mmHg}$ & 1.09 & $0.96-1.23$ & 0.188 \\
\hline Sitting $\mathrm{TcPO}_{2}$ target leg, $\mathrm{mmHg}$ & 1.10 & $0.97-1.24$ & 0.130 \\
\hline Sitting to supine $\mathrm{TcPO}_{2}$ gradient & 1.10 & $0.93-1.30$ & 0.251 \\
\hline Sitting to supine $\mathrm{TcPO}_{2}$ gradient $\geq 15$ & 2.60 & $0.14-50.05$ & 0.527 \\
\hline$A B \mid$ target leg $(\times 100)$ & 1.04 & $0.94-1.15$ & 0.454 \\
\hline CLI with ulcers & 1.13 & $0.18-6.93$ & 0.899 \\
\hline CLI with gangrene & 0.10 & $0.01-1.19$ & 0.068 \\
\hline ARI of foot arteries & 0.00 & $0.00-0.46$ & 0.023 \\
\hline$A R I$ - femoro-distal tract & 0.83 & $0.59-1.18$ & 0.299 \\
\hline ARI - tibial arteries & 0.40 & $0.06-2.74$ & 0.349 \\
\hline ARI - total & 0.86 & $0.63-1.16$ & 0.320 \\
\hline
\end{tabular}

Abbreviations: $A B I$, ankle-brachial index; $A R I$, angiographic resistance index; $\mathrm{Cl}$, confidence interval; $\mathrm{CLI}$, critical limb ischemia; OR, odds ratio; $\mathrm{TcPO}_{2}$, transcutaneous oxygen tension.
Evaluation in the post hoc analysis of the results of all the patients treated with SCS who survived at least 2 months at follow-up, including cases in the I-SCS group, did not show parameters predictive of success. As the results of the logistic regression model included data on just 22 patients, they should be interpreted with caution.

\section{Microcirculatory effects}

In the post hoc analysis, we evaluated the $\mathrm{TcPO}_{2}$ changes between baseline and the early evaluation at 15 days. Baseline and 15-day mean supine $\mathrm{TcPO}_{2}$ values in the iloprost arm increased from a baseline value of $11.9 \% \pm 11 \%$ to $22.0 \% \pm 18.7 \%$ ( $P=0.008$, two-tailed Student's $t$-test for paired data), while sitting $\mathrm{TcPO}_{2}$ values increased from $36.5 \% \pm 12.6 \%$ to $40.6 \% \pm 15.5 \%(P=0.2)$. In the SCS arm, mean $\mathrm{TcPO}_{2}$ values increased from $11.7 \% \pm 9.1 \%$ to $20.9 \% \pm 15.1 \%$ in supine position $(P=0.0037)$ and from $33.8 \% \pm 11.9 \%$ to $40.5 \% \pm 16.9 \%$ in sitting position $(P=0.018)$; the range of the recorded values is wide, as shown by the standard deviations. The 15-day changes were not related to outcome, and did not occur in the same way in each of the two positions. More stable data were obtained in the follow-up.

\section{Discussion}

The spinal cord stimulation or prostacyclin in unrevascularizable arteriopathy of lower limbs (SPINAL) study is the first randomized controlled trial (RCT) comparing SCS and 
iloprost, maintaining the best medical treatment (BMT) in both arms of the study. Moreover, it did not include patients with Buerger's disease or other vascular diseases, but only patients with atherosclerotic occlusions of the great vessels of the lower limbs, associated or not with diabetes. The core laboratory review of imaging, using the same criteria, ensured uniform classification.

Even though endovascular and surgical revascularization allow treatment in an increasing number of patients, their long-term patency is not always relevant, particularly in infragenicular arteries, where thrombosis of distal and foot arteries leads to the impossibility of further revascularization, proven by a stationary incidence of major amputation recorded in Italian and international health service database. So the need for medical or alternative methods to improve vascular perfusion of lower limbs does not decrease.

The utilization of SCS in treatment of CLI is supported by clinical studies (prevalently nonrandomized cohort studies and some RCTs $)^{8-13}$ and by microcirculatory studies, which have shown an increased number of perfused capillaries without an increase in their diameter, ${ }^{14}$ an increase in capillary density at 3 months; ${ }^{5}$ and an increase in the peak-rest erythrocyte velocity during reactive hyperemia. ${ }^{15}$ The first edition of TASC, ${ }^{2}$ however, available when the study was designed, concluded that SCS cannot be recommended on the basis of available studies.

Regarding medical treatment, recommendation 28 of TASC II, about use of prostanoids in CLI, states:

There are no other pharmacotherapies that can be recommended for the treatment of CLI (B). Results of angiogenetic therapy are conflicting, with some good results and with side effects that suggest the necessity of further randomized studies. ${ }^{4}$

The choice of iloprost as prostanoid to be used in our protocol was based on the results of some randomized and prospective studies that demonstrated better results of iloprost treatment versus placebo ${ }^{16}$ and on the results of nine doubleblind randomized trials ${ }^{17-25}$ on prostanoid treatment, reported also in TASC II, of which three prostaglandin (PGE1) studies showed a benefit on reducing ulcer size, but did not show favorable outcomes on other critical clinical endpoints. ${ }^{3}$

The modality of treatment with iloprost, in our protocol, was based on two small RCTs and one prospective trial that showed similar results, but better tolerability and reduced hospital stay, in patients treated with a lower hourly dose for 16 hours per day for 7 days, than with the traditional treatment of 6 hours per day for 28 days. ${ }^{26-28}$
Indication for treatment with SCS was based on the microcirculatory criteria reported in a recent article, ${ }^{6}$ and on the results of the SCS-EPOS study. ${ }^{29}$ The crossover to SCS after prostanoid failure was allowed for ethical purposes while designing the protocol; it can be considered a confounding parameter, but it led to some interesting results, which are useful for patients and for further studies.

The early evaluation was scheduled after around 15 days, since iloprost treatment (corresponding to 28 days' treatment) could be considered completed (treatment should not exceed 4 weeks, with the possibility to repeat the treatment successively). Results, generally positive, can be observed after the first days of treatment; on the contrary, late improvements are rare and are often associated with some worsening in the ischemic area. The efficacy of SCS on pain can generally be observed within a few days. Generally, a 15-day delay enables a reliable evaluation of changes of the ischemic limb.

The analyses presented here were done with a sample smaller than the sample calculated to achieve the statistical significance for the primary endpoint evaluation. It was, however, correctly randomized, with no differences between the two arms. The severity of ischemia was documented by low $\mathrm{TcPO}_{2}$ values in supine position, even if with a preserved increase greater than $10 \mathrm{mmHg}$ in sitting position. Mean ABI values seem relatively high; however, $\mathrm{ABI}$ was measurable only in $44.6 \%$ of cases, so in more than $55 \%$ of cases, no blood flow was documentable in the tibial arteries at the ankle, confirming the severity of the evaluated sample. The classification of unrevascularizability was restrictive, to avoid the frequent cases of not true revascularizability secondary to absence of a good venous conduit, in which results of SCS are significantly better. ${ }^{30}$ The core laboratory review of morphological data was performed in all patients, avoiding misinterpretations.

At the early clinical efficacy evaluation, results showed that SCS was significantly better than iloprost in pain reduction, had fewer cases of worsening of the ischemic lesions, and was better tolerated.

Regarding the primary endpoint (limb salvage at 12 months) and the ad interim analysis of the same parameter at 2 months, SCS and iloprost did not show any significant difference. The 1-year limb salvage is also discussed in the post hoc evaluation.

This study did not recruit sufficient patients to evaluate the primary endpoint of limb salvage at 1 year - therefore, the failure to demonstrate a statistically significant difference between the SCS and iloprost arms may not be due to failure 
of SCS. Larger international trials are likely to be needed to address this issue definitively.

Regarding secondary endpoints, iloprost treatment was followed by a better, although not significant, 1-year survival rate and lower incidence of minor amputations.

Improved survival following iloprost treatment has been observed even in the ILoprost in Acute Ischemia of Lower Limbs (ILAILL) study, ${ }^{31}$ in which iloprost was infused for 4-7 days (full treatment only in 34.9\%) after surgery for acute ischemia. Duration of treatment and dose of administered drugs were similar to the dose administered to our patients who interrupted the study due to inefficacy or adverse events. The effects on early and late mortality can likely be ascribed to the effects on platelet activation and blood clotting, to the reduction of free radicals and cytokine production, and to lower expression of intercellular adhesion molecules, described in different patient populations. ${ }^{32,33}$ The effects of the other medical treatment cannot be evaluated; however, all patients were on antiplatelet or anticoagulant treatment, and nearly all patients had similar treatment of their risk factors with statins and antihypertensive drugs.

SCS significantly reduced pain in the majority of the patients. Pain reduction or pain relief up to $94 \%$ is well documented in all publications, ${ }^{34}$ and occurs at a higher rate than with prostanoid treatment, independent of circulatory changes, but, in particular, in patients with a good increase in the blood flow. ${ }^{35}$

In our sample, pain reduction was observed, at the follow-up visit at $15 \pm 3$ days post-randomization, in all patients of the SCS group except one, who underwent major amputation, and only in eleven of 27 patients treated with iloprost. Pain reduction or relief was greater in the SCS group. Pain relief is an important factor in the quality of life, since it allows patients to survive with their ulcers without requiring a leg amputation. Moreover, the quicker action of SCS on pain gives medical treatment a better chance to improve microcirculation with a consequent greater probability to increase limb salvage, as shown in another study in which prostanoids were administered before or together with SCS. ${ }^{36}$

Quality of life and disability status, such as economic evaluation, and relationships between stimulation parameters and results of SCS were not analyzed for this report.

In the post hoc analysis, considering the patients who switched over from iloprost to SCS, we did not find any significant difference in survival and limb salvage rates, probably due to the small sample; however, SCS implantation after a failed iloprost treatment was followed by a lower incidence of amputation and a longer survival rate, with significant differences in the comparison of combined treatment versus each single treatment. These results are similar to those obtained in another study in patients with better anatomic conditions, all treated with the BMT, including prostanoids: at 1-year follow-up, $74.9 \%$ of patients at Leriche-Fontaine stage III and $54.7 \%$ at stage IV were alive without amputation. ${ }^{36}$

In the multivariate analysis of our sample we did not find any independent predictive values of long-term success following SCS; however, the presence of some arteries at the foot and the absence of gangrene were associated in the univariate evaluation with a higher probability to avoid a limb amputation. As was found in another study, ${ }^{36}$ diabetes was not a predictive value of limb amputation in the SCS arm, since the inhibition of sympathetic activity is not the only neurophysiological mechanism of action of SCS. The results in diabetic patients are quite different in other reported in a review and seem to be worse in patients with autonomic neuropathy. ${ }^{21}$ Microcirculatory predictive parameters described by Gersbach et al were not confirmed in this study. ${ }^{5}$ The cut-off of $10 \mathrm{mmHg}$ of $\mathrm{TcPO}_{2}$ cannot be used to contraindicate the implantation of an SCS, as 8/13 (61.5\%) patients with $\mathrm{TcPO}_{2}<10 \mathrm{mmHg}$ surviving at 6 months avoided leg amputation.

Regarding safety, in the SCS arm, the three severe related events, all surgical site infection including lead or stimulator, were resolved with the explant, while in the iloprost arm, we recorded a probably related fatal event; moreover, the high number cases of intolerance and side effects of iloprost suggest that SCS is better tolerated and safer than iloprost. Prevention of surgical-site infection when treating patients with gangrene probably needs an antibiotic treatment, not only a short preoperative prophylaxis.

As for renal function, we are not aware of cases of deterioration related to the use of PGI2 analog reported in literature; however, in our sample, we recorded a mild increase of serum creatinine in spite of good hydration and reduction of nonsteroidal anti-inflammatories (NSAIDs).

Currently, the results of only five RCTs have been published. Among these, only one was conducted versus a defined medical treatment (PGE1), ${ }^{11}$ while the others in the control group reported a generic BMT, ${ }^{12,37}$ analgesics, ${ }^{10}$ or BMT plus analgesic and vasoactive drugs. ${ }^{38}$ The epidural spinal electrical stimulation (ESES) study enrolled the largest number of cases (120 patients), ${ }^{12}$ followed by the studies of Claeys and Horsch (86 patients), ${ }^{11}$ Jivegård et al (51 cases), ${ }^{10}$ Spincemaille et al (37 cases), ${ }^{38}$ and Suy et al (38 patients including Buerger's disease). ${ }^{37}$ 
Although incomplete, the SPINAL study evaluated a sample greater than those of these three available RCTs (treating 55 limbs in 52 patients).

\section{Conclusion}

This study shows the difficulties in reaching a consistent sample for an RCT for unrevascularizable critical limb ischemia in the era of endovascular treatment, suggesting for future studies the need to involve many more centers or to use registries.

In the SPINAL study, SCS was demonstrated to be a quick and better answer to pain, with better tolerability and better early results. While it did not significantly improve the 1-year limb salvage rate, the rate was better after a Iloprost plus SCS combined treatment (100\%) or SCS (66.8\%) than after prostacyclin $(57.1 \%)$ in the per-treatment analysis, confirming other studies that have shown a trend toward a better amputation-free salvage in the SCS group, such as that reported by Ubbink and Vermeulen in a 2005 Cochrane Review. ${ }^{39}$ One should take the very low statistical power and possible type II errors into account.

The results of this trial suggest that prostanoids and SCS are not alternative treatments; as iloprost seems to result in better survival, it should be used first and should be repeated in the follow-up as its effects on ischemia tend to decrease, while SCS is more effective against pain and limb salvage.

Since prostanoid treatments have many contraindications and are complicated by many side effects, SCS can be considered the complementary and consecutive management for patients who are no longer treatable with open or endovascular revascularizations and who do not respond to prostanoids, and/or as an alternative treatment in patients who cannot be treated with prostanoids. Moreover, results in the nine patients with combined treatment suggest that the combination of both therapies seems to increase the 6-month limb salvage rate, in particular, in patients with $\mathrm{TcPO}_{2}<10 \mathrm{mmHg}(100 \%$ limb salvage versus $44.4 \%$ with SCS alone and $55.5 \%$ with iloprost treatment) and in patients without ulcers or gangrene. Generally, the association of iloprost and SCS, when feasible, seems to produce a synergic activity even in patients who had a very short and ineffective prostanoid treatment; the action mechanism should be further investigated and results confirmed with a greater sample. Finally, SCS provides continuous effects, while the effect of prostanoids is short and repeated treatments are required.

As the presence of better vascularization at foot level is associated with better results, we can surmise that the treatment is likely to lead to better results in patients with non-anatomical contraindications to revascularization.

\section{The SPINAL Study Group}

The SPINAL Study Group is: Coordinating center: Operative Unit of Vascular Surgery, Maggiore Hospital of Bologna (Pedrini L, Ballestrazzi MS, Magnoni F). Principal investigator: Pedrini L, Bologna; core lab analysis: Pedrini L, Bologna. Other investigators: Antico A, Operative Unit of Vascular Surgery, Ospedale Regional Hospital of Valle D'Aosta, Aosta (actual address: Private Hospital "L Pierangeli," Pescara); Antignani PL, Div of Angiology, AO "San Giovanni Addolorata", Roma (member of the steering committee); Bertoletti G, Genovese V (now deceased), Operative Unit of Vascular Surgery, S Maria Goretti Hospital, Latina; Castrucci T, Operative Unit of Vascular Surgery, S Eugenio Hospital, Roma; Jannello AM, Pruner G, Operative Unit of Vascular Surgery, Sacro Cuore Don Calabria Hospital, Negrar; Palombo D, Mazzei R (now deceased), Operative Unitand Chair of Vascular Surgery, AOS Martino, Genova; Pellegrino C, Surgical Dept AOU “Ospedali Riuniti” Foggia; Perkmann R, Operative Unit of General Surgery, Vascular section, AS Bressanone (actual address: Operative Unit of Vascular and Thoracic Surgery, Hospital of Bolzano); Rispoli P, Operative Unit and Chair of Vascular Surgery, AOS Giovanni Battista “Le Molinette," Torino; Settembrini P, Dallatana R, Operative Unit and Chair of Vascular Surgery, A O San Carlo Borromeo, Milano; Spigonardo F, D'Orazio M, Operative Unit of Vascular Surgery, SS Annunziata Clinical Hospital, Chieti; Tori A, Chierichetti F, Operative Unit of Vascular Surgery, Circle Hospital, Busto Arsizio; Udini M, Comandatore L, Operative Unit of Vascular Surgery, AOE Morelli, Sondalo.

\section{Acknowledgment}

The authors thank the Centres of Vascular Surgery that participated in the SPINAL study and the patients included in this study for their trust and support.

\section{Author contributions}

Conception and design and central researcher, LP; all authors contributed toward data analysis, drafting, and revising the paper and agree to be accountable for all aspects of the work; overall responsibility, LP.

\section{Disclosure}

Dr Pedrini reports receiving consulting fees for the development of the clinical trial design and management. This trial 
was sponsored by Medtronic Italy. Randomization procedure by Quintalis. The authors report no other conflicts of interest in this work.

\section{References}

1. Bradbury AW, Adam DJ, Bell J, et al; BASIL trial Participants. Bypass versus Angioplasty in Severe Ischaemia of the Leg (BASIL) trial: analysis of amputation free and overall survival by treatment received. J Vasc Surg. 2010;51(Suppl 5):18S-31S.

2. TASC (TransAtlantic Inter-Society) working group. Consensus. Management of peripheral arterial disease (PAD). Int Angiol. 2000;19:S1-N $\mathrm{N}^{\circ} 1: 1-310$.

3. Ubbink DT, Vermeulen H. Spinal cord stimulation for nonreconstructable chronic critical leg ischaemia. Cochrane Database Syst Rev. 2003;(3):CD004001.

4. Norgren L, Hiatt WR, Dormandy JA, et al; TASC II Working Group. Inter-society consensus for the management of peripheral arterial disease. Int Angiol. 2007;26(2):81-157.

5. Gersbach P, Hasdemir MG, Stevens RD, Nachbur B, Mahler F. Discriminative microcirculatory screening of patients with refractory limb ischaemia for dorsal column stimulation. Eur J Vasc Endovasc Surg. 1997;13:464-471.

6. Spincemaille GH, de Vet HC, Ubbink DT, Jacobs MJ. The results of spinal cord stimulation in critical limb ischaemia: a review. Eur JVasc Endovasc Surg. 2001;20:99-105.

7. Rutherford RB, Baker JD, Ernst C, et al. Recommended standards for reports dealing with lower extremity ischemia: revised version. $J$ Vasc Surg. 1997;26:517-538.

8. Gersbach PA, Argitis V, Gardaz JP, von Segesser LK, Haesler E. Late outcome of spinal cord stimulation for unreconstructable and limbthreatening lower limb ischemia. Eur J Vasc Endovasc Surg. 2007;33(6): $717-724$.

9. Galley D, Rettori R, Boccalon H, et al. [Electric stimulation of the spinal cord in arterial diseases of the legs. A multicenter study of 244 patients]. J Mal Vasc. 1992;17(3):208-213. French.

10. Jivegård LE, Augustinsson LE, Holm J, Risberg B, Ortenwall P. Effects of spinal cord stimulation (SCS) in patients with inoperable severe lower limb ischaemia: a prospective randomised controlled study. Eur J Vasc Endovasc Surg. 1995;9(4):421-425.

11. Claeys LG, Horsch $\mathrm{S}$. Transcutaneous oxygen pressure as predictive parameter for ulcer healing in endstage vascular patients treated with spinal cord stimulation. Int Angiol. 1996;15(4):344-349.

12. Klomp HM, Spincemaille GH, Steyerberg EW, Habbema JD, van Urk H. Spinal-cord stimulation in critical limb ischaemia: a randomised trial. ESES Study Group. Lancet. 1999;353(9158):1040-1044.

13. Bruni T, Ghizzi M, Tedoli M, Bellani A, Paladini R. [Treatment of chronic critical ischemia of the lower limbs with spinal cord electrostimulation]. Chir Ital. 1999;51(1):53-58. Italian.

14. Jacobs MJ, Jörning PJ, Beckers RC, et al. Foot salvage and improvement of microvascular blood flow as a result of epidural spinal cord electrical stimulation. J Vasc Surg. 1990;12:354-360.

15. Ubbink DT, Spincemaille GH, Prins MH, Reneman RS, Jacobs MJ. Microcirculatory investigations to determine the effect of spinal cord stimulation for critical limb ischemia: the Dutch multicenter randomized controlled trial. J Vasc Surg. 1999;30:236-244.

16. Balzer $\mathrm{K}$, Bechara $\mathrm{G}$, Bisler $\mathrm{H}$, et al. Reduction of ischaemic pain in advanced peripheral arterial occlusive disease. A double blind placebo controlled trial with iloprost. Int Angiol. 1991;10:229-232.

17. Balzer K, Bechara G, Bisler H et al. Placebo-kontrollierte, doppel-blinde Multicenterstudie zur Wirksamkeit von Iloprost bei der Behandlung ischa"mischer Ruheschmerzen von Patienten mit peripheren arterillen Durchblutungsstorungen. Vasa. 1987;20:379-381. German.

18. Brock FE, Abri O, Baitsch G, et al. Iloprost in the treatment of ischemic tissue lesions in diabetics. Results of a placebo-controlled multicenter study with a stable prostacyclin derivative. Schweiz Med Wochenschr.1990;120(40): 1477-1482.
19. Diehm MC, Abri O, Baitsch G, et al. Iloprost, a stable prostacyclin derivative, in stage 4 arterial occlusive disease. A placebo-controlled multicenter study. Dtsch Med Wochenschr 1989;114(20):783-788.

20. Diehm C, Hibsch-Miller C, Stammler F. Intravenose prostaglandin E1-therapie bei patienten mit peripherer arterieller verschlusskrankheit (AVK) im Stadium III: Eine doppelblinde, placebo-kontrollierte studie. In: Heinrich H, Bohme H, Rogatti W, eds. Prostaglandin E1-Wirkungen und therapeutische Wirksamheit. Heidelberg, Springer-Verlag; 1988:133-143. German.

21. Ciprostene Study Group. The effect of ciprostene in patients with peripheral vascular disease (PVD) characterized by ischemic ulcers. J Clin Pharmacol. 1991;31:81-87.

22. UK Severe Limb Ischemia Study Group. Treatment of limb threatening ischemia with intravenous Iloprost: A randomized double-blind placebo controlled study. Eur J Vasc Surg 1991;5:511-516.

23. Guilmot J, Diot E, for the French Iloprost Study Group. Treatment of lower limb ischaemia due to atherosclerosis in diabetic and nondiabetic patients with iloprost, a stable analoque of prostacyclin: results of a French Multicentre trial. Drug Invest. 1991;3:351-359.

24. Norgren L, Alwmark A, Angqvist KA, et al. A stable prostacyclin analogue (iloprost) in the treatment of ischaemic ulcers of the lower limb. A Scandinavian-Polish placebo controlled, randomised multicenter study. Eur J Vasc Surg. 1990;4(5):463-467.

25. Sakaguchi S. Prostaglandin E1 intra-arterial infusion therapy in patients with ischemic ulcer of the extremities. Int Angiol.1984;3:39-42.

26. Arosio E, Sardina M, Prior M, De Marchi S, Zannoni M, Bianchini C. Clinical and circulatory effects of Iloprost either administered for 1 week or 4 weeks in patients with peripheral obstructive arterial disease at Leriche-Fontaine stage III. Eur Rev Med Pharmacol Sci. 1998;2: 53-59.

27. Ceriello A, Sardina M, Motz E, Lizzio S, Tuniz D, Bianchini C. Effects of iloprost, either administered for 1 week or 4 weeks, on systemic hemodynamics, peripheral blood flow, and exercise tolerance in patients with peripheral occlusive arterial disease at Leriche-Fontaine stage III. Int Angiol. 1998;7:23-33.

28. Minnucci A, Agostinis M. Iloprost: a new simplified therapeutical regimen in patients with peripheral occlusive arterial disease (PAOD) al LericheFontaine stage III and IV. Internal Medicine. 1999;7:87-90.

29. Amann W, Berg P, Gersbach P, Gamain J, Raphael JH, Ubink DT; European Peripheral Vascular Disease Outcome Study SCS-EPOS. Spinal cord stimulation in the treatment of non-reconstructable critical leg ischaemia: results of the European Peripheral Vascular Disease Outcome Study (SCS-EPOS). Eur J Vasc Endovasc Surg. 2003;26(3): 280-286.

30. Pedrini L, Magnoni F. Spinal cord stimulation for lower limb ischemic pain treatment. Interact Cardiovasc Thorac Surg. 2007;6(4): 495-500.

31. de Donato G, Gussoni G, de Donato G, et al. The ILAILL study: iloprost as adjuvant to surgery for acute ischemia of lower limbs: a randomized, placebo-controlled, double-blind study by the italian society for vascular and endovascular surgery. Ann Surg. 2006;244(2):185-193.

32. Mazzone A, Mazzucchelli I, Fossati G, et al. Iloprost effects on phagocytes in patients suffering from ischaemic diseases: in vivo evidence for down-regulation of alpha M beta 2 integrin. Eur J Clin Invest. 1996;26:860-866.

33. Mazzone A, Faggioli P, Cusa C, Stefanin C, Rondena M, Morelli B. Effects of iloprost on adhesion molecules and $\mathrm{F} 1+2$ in peripheral ischemia. Eur J Clin Invest. 2002;32:882-888.

34. Ubbink DT, Jacobs JHM. Spinal cord stimulation in critical limb ischemia. In: Branchereau A, Jacobs M, editors. Critical Limb Ischemia. Armonk, NY: Futura Publishing Company, Inc.; 1999:75-84.

35. Ghajar AW, Miles JB. The differential effect of the level of spinal cord stimulation on patients with advanced peripheral vascular disease in the lower limbs. Br J Neurosurg. 1998;12:402-408.

36. Pedrini L, Gregorini P, Magnoni F, Ballestrazzi MS, Sensi L, Pisano E. Spinal cord stimulation for untreatable critical limb ischemia: experience and late results of a single centre. J Vasc Endovasc Surg. 2008;15:223-230 
37. Suy R, Gybels J, Van Damme H, Martin D, vanMaele R, Delaporte C. Spinal cord stimulation: an innovative method in the treatment of PVD. In: Horsch S, Claeys L, editors. An Innovative Method in the Treatment of PVD. Darmstadt: Steinkopff; 1994.

38. Spincemaille GH, Klomp HM, Steyerberg EW, Habbema JD. Spinal cord stimulation in patients with critical limb ischemia: a preliminary evaluation of a multicentre trial. Acta Chir Austriaca. 2000;32: $49-51$.
39. Ubbink DT, Vermeulen H. Spinal cord stimulation for nonreconstructable chronic critical leg ischaemia. Cochrane Database Syst Rev. 2005;(3):CD004001.

\section{Publish your work in this journal}

Journal of Vascular Diagnostics is an international, peer-reviewed journal of diagnostics, focusing on non invasive vascular investigation methods involved in the evaluation of vascular diseases. The journal is committed to the rapid publication in the fields of vascular diseases. Original research, review, case reports, expert opinion and commentaries

\section{Dovepress}

are all considered for publication. The manuscript management system is completely online and includes a very quick and fair peer-review system, which is all easy to use. Visit http://www.dovepress.com/testimonials.php to read real quotes from published authors.

Submit your manuscript here: http://www.dovepress.com/journal-of-vascular-diagnostics-journal 